\title{
CEP 16-09
}

\section{Entrepreneurship and the Business Cycle: Stylized Facts from U.S. Venture Capital Activity \\ Hashmat Khan \\ Carleton University \\ Pythagoras Petratos \\ Saïd Business School \\ Oxford University}

June 2016

\section{CARLETON ECONOMIC PAPERS}
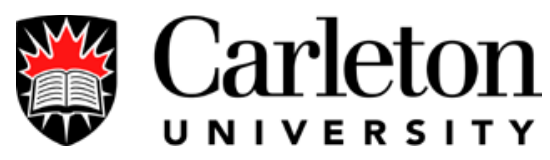

Department of Economics

1125 Colonel By Drive Ottawa, Ontario, Canada K1S 5B6 


\title{
Entrepreneurship and the Business Cycle: Stylized Facts from US Venture Capital Activity
}

\author{
Hashmat Khan* \\ Department of Economics \\ Carleton University
}

\author{
Pythagoras Petratos ${ }^{\dagger}$ \\ Said Business School \\ Oxford University
}

June 2016

\begin{abstract}
We consider US Venture Capital (VC) activity as a measure of entrepreneurship and study its relationship with the business cycle. This measure addresses some biases in alternative measures such as self-employment and business ownership that have been considered in previous literature. Despite the well-known volatility in VC activity, it remains an important source of funding for entrepreneurs engaging in innovative business creation. We document key stylized facts for VC entry (seed and start-up stage) and VC exit (late stage) at the aggregate and sectoral level. VC entry is more strongly correlated and is contemporaneous with the business cycle while VC exit lags the cycle by two quarters. There is strong evidence for a bi-directional causality between entrepreneurship and economic activity. A positive shock to VC activity has a positive effect on real GDP. Our findings can help inform policies designed to support entrepreneurship.
\end{abstract}

JEL classification: E32, G24, L26

Key words: Entrepreneurship, Venture Capital, Business Cycles

${ }^{*}$ E-mail: hashmat.khan@carleton.ca. Khan acknowledges financial support of Carleton Development Grant (2015-2016).

${ }^{\dagger} E$-mail: pythagoras.petratos@sbs.ox.ac.uk. Petratos acknowledges the support of library services at Said Business School, and especially Chris Flegg, the Head Librarian, for obtaining the database. 


\section{Introduction}

What is the relationship between entrepreneurship and the business cycle? Despite the wellrecognized importance of entrepreneurial activity in an economy, there is surprisingly little empirical evidence (Koellinger and Thurik (2012); Parker, Congregado, and Golpe (2012)). ${ }^{1}$ A key challenge in empirical work is that entrepreneurship cannot be easily captured by a single measure. Koellinger and Thurik (2012) use business ownership data but recognize that it does not capture early-stage venture, which can encompass highly innovative activity despite generating only little revenues. Parker, Congregado, and Golpe (2012) use self-employment data which has its limitations, especially under-sampling innovative entrepreneurs. In fact, Parker, Congregado, and Golpe (2012) note that entrepreneurship is a multifaceted concept, a single measure might not do justice. ${ }^{2}$ Building on this point, we consider a novel alternative measure of entrepreneurship and contribute to the existing empirical evidence on the question posed above.

We measure entrepreneurship using quarterly Venture Capital (VC) data for the US from 1990 to 2014, and document business cycle stylized facts. Specifically, there are two key components to the data: first, the number of new VC-funded business formation representing entrepreneurial entry (the seed and start-up stage), and second, the number of successful exits from the VC stage in the form of IPOs, secondary and trade sales (i.e. mergers and acquisitions). VC exit represents the late and mature stage of entrepreneurial activity. Despite the well-known volatility due to the high risk-high return nature of $\mathrm{VC}$ activity, venture capital remains an important source of funding for entrepreneurs engaging in innovative activity in the information technology, medical/health and life sciences sectors. Understanding the relationship of this type of innovative entrepreneurial activity with the business cycle is, therefore, important for academics, venture capital participants, and policy makers. To the best of our knowledge, our paper is first to study the relationship of VC entrepreneurial activity with the business cycle.

\footnotetext{
${ }^{1}$ Earlier work of Audretsch and Acs (1994), Golpe (2009), Faria, Cuestas, and Gil-Alana (2009), Faria, Cuestas, and Mourelle (2010) present common features with our study but they are not directly related to the specific topic under investigation.

2 Parker, Congregado, and Golpe (2012), page 749, write in the context of understanding entrepreneurship and the macro-business cycle: "... more research remains to be done. One important avenue for future work is to obtain time series data for different measures of entrepreneurship, for example Schumpeterian Innovation. Alternative measures of entrepreneurship might exhibit different cyclical relationships.".
} 
Our measure has at least four advantages. First, it covers the entire population of VC funded companies in the US over the past 25 years and includes three NBER-dated business cycle periods. Second, academic literature and Eurostat/OECD (2007) indicate that VC activity effectively captures entrepreneurial activity and innovation. Third, our measure can diminish biases in existing entrepreneurship measures. For example, the "recession push" and "prosperity pull" effects could be reduced, since individuals are less likely to be "pushed" by a recession and "pulled" by a boom into VC funded entrepreneurship as an alternative to other forms of employment. This important aspect is due to some distinct characteristics and barriers in the VC industry. Fourth, we can compare and contrast the relationship of both aggregate and sector VC-funded entrepreneurial activity with the business cycle.

We document three sets of stylized facts and quantify them using (i) correlations, crosscorrelations, volatility (ii) Granger-causality, and (iii) a dynamic analysis using vector autoregressions (VARs) to determine how shocks to VC activity and Real Gross Domestic Product (GDP) affect each other. Entrepreneurial activity as captured by VC entry and exit is procyclical. That is, both VC entry and exit tend to increase during an economic expansion and decrease during a recession. Cyclical VC entry has a strong contemporaneous correlation of 0.6 with cyclical GDP. VC exit, however, is less procyclical with a correlation of 0.26 , and lags the US business cycle by two quarters. Notably, our VC-based measure of entrepreneurship is relatively more procyclical than those in the previous literature. In particular, Koellinger and Thurik (2012) report a low average contemporaneous correlation of 0.06 between global cyclical GDP and the business ownership-based entrepreneurship measure. Parker, Congregado, and Golpe (2012) report a correlation of 0.05 between cyclical GDP and self-employment based entrepreneurship measure for the UK.

$\mathrm{VC}$ activity is highly volatile. VC entry is nearly three times and $\mathrm{VC}$ exit is nearly five times as volatile as business fixed investment, respectively. In this context, VC activity resembles the extreme volatility of inventory investment, which like VC activity is a small share of GDP, yet accounts for nearly half of the decline in GDP during a recession (Khan (2003)).

The sectoral patterns, in general, are similar to aggregate in both VC entry and exit, respectively. VC entry in the investment technology (IT) sector is most strongly correlated with the business cycle, followed by life sciences (LS). VC entry in the non-high-technology (NHT) is the 
least correlated with the business cycle. Turning to sectoral VC exit, we find that IT and NHT are relatively more procyclical than LS. All three sectors, however, lag the US business cycle. In particular, VC exit in the IT and NHT sectors lags by one quarter, and in the LS sector it lags by two quarters.

Granger-causality tests reveal that the relationship of VC entry and exit with the US business cycle is bi-directional. Put differently, VC activity predicts future GDP and vice versa. Previously, Parker, Congregado, and Golpe (2012) found similar bi-directional causality in UK data with selfemployment-based measure of entrepreneurship. The similarity of our finding at the aggregate level with theirs is remarkable because both the entrepreneurship measures and the countries are different. Similar bi-directional causality between VC activity and GDP is also present in the three sectors with one exception. VC exit in the IT sector does Granger-cause GDP.

We conduct a VAR analysis to determine how a VC entry or exit shock affects cyclical GDP, and how a GDP shock affects cyclical VC activity. In each case we find that the responses of cyclical VC activity and GDP are hump-shaped. The increase in cyclical GDP after an VC shock is consistent with the finding in Koellinger and Thurik (2012). They show that cyclical global GDP rises after a global entrepreneurship shock. We find, however, that GDP shock has relatively stronger effect on VC activity. The GDP shock accounts for about 30 percent of the variation in $\mathrm{VC}$ entry at a 8 quarter horizon and about 5 percent of the variation in $\mathrm{VC}$ exit. By contrast the VC shocks account for only a small fraction of the variation in cyclical GDP. Relative to Parker, Congregado, and Golpe (2012), the share of GDP shock in accounting for the variation in our VC-based entrepreneurship measure is approximately similar at the 8 quarter horizon. However, the share of the entrepreneurship shock in accounting for the variation is cyclical GDP is relatively small compared to Parker, Congregado, and Golpe (2012). ${ }^{3}$

Given the importance of VC activity in the creation of major enterprises, there is much attention paid to it from a public policy perspective. Our stylized facts indicated that entrepreneurship, looking through the lens of VC activity, is procyclical. One concern is that recessions may lead to a decrease in innovation oriented entrepreneurial activity that may have detrimental effects on

\footnotetext{
${ }^{3}$ Koellinger and Thurik (2012) do not provide variance decomposition results for the entrepreneurship shock so we cannot make a comparison of how findings differ between their entrepreneurship measure and ours.
} 
the economy, and could potentially delay the subsequent recovery. The role of public policy can be helpful in this context. Brander, Du, and Hellmann (2014), for example, have pointed out the importance of government-sponsored VC and that it augments, as opposed to 'crowding-out', private VC activity. Our stylized facts suggest that taking into account the cyclicality of VC activity in designing policies aimed at supporting entrepreneurship could be beneficial for the society.

The rest of the paper is organized as follows. Section 2 summarizes important literature connected to various aspects of the paper. Section 3 describes the data and its advantages. Section 4 presents the stylized facts. Section 5 presents some policy implications of our findings. Section 6 concludes.

\section{Related literature}

\subsection{Theoretical Studies of Entrepreneurship and Business Cycles}

The early work of Schumpeter (1934) discussed how the behavior of entrepreneurs affects the

business cycle. According to Schumpeter business cycles can be attributed to different group of forces; as savings and accumulation, and innovations by entrepreneurs who develop new ways of production (Kuznets (1940)). Bernanke and Gertler (1989) formalize these ideas by constructing a modified real business cycle model in which information asymmetries exist between entrepreneurs and savers. This type of financial friction generates a procyclical net worth of entrepreneurs and an amplification mechanism for shocks to the economy. Entrepreneurs are more solvent during economic booms and hence funding is procyclical. Similarly, Carlstrom and Fuerst (1997) quantify the importance of the qualitative mechanism discussed in Bernanke and Gertler (1989) and show how it affects US output and investment dynamics.

Rampini (2004) also directly linked entrepreneurship and the business cycle. The argument is that entrepreneurial activity is procyclical because of the risk associated with it. More precisely, he suggested that entrepreneurs (agents) who take risky projects need to bear part of the project specific risk and are more willing to bear risk when productivity is high, thus making entrepreneurial activity procyclical, even under optimal contract. The model of Rampini (2004), despite recognizing the existence of countercyclical agency costs, abstracts from financial intermediaries and associated 
funding constraints, but rather focuses on the risk connected to entrepreneurial activity. It follows the work of Knight (1921), who hypothesized that it is more probable that less risk averse individuals would start up a firm. Kihlstrom and Laffont (1979) analyze entry and exit dynamics in a general equilibrium framework and find that more risk averse individuals become workers rather than entrepreneurs. In a similar spirit, Rampini (2004) examined the wealth effects that imply the variation of risk aversion over the business cycle, and thus provides a business cycle version of Knight's theory.

\subsection{Empirical Evidence on Entrepreneurship and Business Cycles}

Koellinger and Thurik (2012) explore the relationship between entrepreneurship and the business cycle both globally and at the national levels. Their measure of country-specific entrepreneurship is annual, and represents the share of business owners in the total labor force. ${ }^{4}$ They find that entrepreneurship Granger-causes the global business cycles, but not necessarily at the national level. Analyzing panel data from 22 OECD countries for the period of 1972 to 2007, their evidence suggests that in only 7 of these countries, entrepreneurship Granger-causes the respective national business cycles, with most statistical significance for the US.

Previous literature documents the procyclical nature of entrepreneurship using measures different from ours (Parker, Congregado, and Golpe (2012); Pardo (2012, 2013)). Parker, Congregado, and Golpe (2012), using quarterly UK self-employment data from 1978 to 2010, find that the dominant pattern is of procyclical entrepreneurship, although this result varies across different sub-periods. Moreover, based on Granger-causality tests they find that this relationship in the UK data is bi-directional.

There is evidence that risk aversion of private entrepreneurs affects business cycles (Pardo (2012)). This effect should be more prevalent in countries that entrepreneurs are relatively more important in the economy. Pardo (2012) finds that this is true for smaller economies, with stronger privately held sectors, but not in countries like US, where the corporate sector is relatively more important.

\footnotetext{
${ }^{4}$ Business ownership includes incorporated, self-employed individuals (owner- managers of incorporated businesses) and (unincorporated) self-employed persons with and without employees, and excludes unpaid family workers.
} 


\section{Data}

The GDP series is quarterly, seasonally adjusted at the annual rate, and in billions of chained 2009 dollars. ${ }^{5}$

\subsection{VC Entry and Exit Data}

We employ VC data from Thomson One, previously known as VentureXpert and Venture Economics. Thomson One, a division of Thomson Reuters, is most popular VC data compared to other commercial databases (Da Rin, Hellmann, and Puri (2013)). ${ }^{6}$ The dataset covers the period from 1st of January 1990 to 31st of December 2014, and includes only completed financial deals. This period witnessed the last three US recessions as dated by NBER. ${ }^{7}$ A major advantage is that this database represents the whole population of VC activity in the US, and hence a good representative of innovative entrepreneurial activity.

The database consists of quarterly VC entry and exit in the US for the period 1990-2014. It consists of 105,202 entries of new companies and 11,548 deals of companies that survive and exit. $\mathrm{VC}$ entry is represented by the number of new business formation and VC exit by the number of IPOs, secondary and trade sales (i.e. mergers and acquisition). VC exit represents firms that grow, survive, and successfully transition into the public markets (IPOs) or private markets (trade sale). However, the concept of VC exit is different in the macroeconomic literature, referring to the companies that do not survive.

\subsection{Sectoral Data}

In addition to the aggregate measures of VC entry and exit, we split our dataset to industry classes of the two categories. Thomson One separates the data into main industrial classes, IT, LS and NHT. Non-High technology class can be considered to have more similarities with manufacturing data.

\footnotetext{
${ }^{5}$ The series label is GDPC1 which we obtained from the FRED database at the Federal Reserve Bank of St. Louis.

${ }^{6}$ The other widely used Venture Capital Database is Venture One, a division of Dow Jones. However, as Thomson One is utilized more extensively by academics, it is the most popular commercial database (Da Rin, Hellmann, and Puri (2013)).

${ }^{7}$ See NBER business cycle dates.
} 


\subsection{VC data Reduces Recession Push and Prosperity Pull Biases}

There is a distinction between marginal entrepreneurs, who have limited impact on the macroeconomy, and high-growth/nonmarginal entrepreneurs that are likely to have a pronounced effect (Koellinger and Thurik (2012)). There are numerous examples of successful VC-financed startups, which grew rapidly and generated substantial employment and economic value, like Google, Medtronic and Home Depot. Therefore despite the relative limited size of the VC market it can have a significant effect on the economy. In addition, high-growth entrepreneurs react more to risky business opportunities than employment (Douglas and Shepherd (2000); Bowen and De Clercq (2008)). Venture capital activity usually implies higher risk than other entrepreneurial projects (Sahlman (1990); Cochrane (2005)).

The previous discussion regarding risk hints that the effects of "recession push" and "prosperity pull" (Parker (2009)) could diminish when measure entrepreneurship using VC data. The dataset contains less risk averse entrepreneurs, could significantly reduce such effects and one would be able to better observe the relationship between entrepreneurship and business cycles. This is due to the fact that more risk loving entrepreneurs would anyway prefer (high growth) entrepreneurial activity rather than merely regard it as an alternative to unemployment. In addition to attitude towards risk, there are other entrepreneurial characteristics that are more intense in VC activity. They can constitute barriers to VC entry and exit, in comparison to marginal/replicative entrepreneurial activity. Most notably, studies have demonstrated that education appears to be important for high-technology firms (Roberts (1968); Cooper (1971); Van de Ven, Hudson, and Schroeder (1984); Jo and Lee (1996)) but not in general entrepreneurial settings (Hoad and Rosko (1964); Douglass (1976); Sandberg and Hofer (1987)). These characteristics constitute barriers that prevent the possibilities of unemployed to embark upon entrepreneurship. Consequently "push" and "pull" biases are diminished in the VC data.

\section{Stylized Facts}

In this section we present the stylized facts based on aggregate and sectoral analysis. Since our focus is on understanding the relationship between VC activity and business cycles, the analysis is 
based on the cyclical components of VC entry and exit, and GDP. To obtain the cyclical component, we use the Hodrick-Prescott (HP) filter with a smoothing parameter of 1600, commonly used in empirical business cycle analysis.

\subsection{Correlations and Cross-Correlations}

\section{i. Correlations and volatility}

Figure 1 shows the cyclicality in the aggregate entry of VC-funded companies and real GDP. There is a strong comovement pattern. The correlation between the two variables is 0.6. VC entry declines sharply during recessions followed by a somewhat gradual recovery. VC entry also varies a lot over the business cycle. The cyclical volatility of VC entry relative to GDP is 15.14 over the sample period. To put this in perspective, that is over three times the volatility of business fixed investment in the U.S. economy. The cyclical volatility of VC exit is even higher, nearly 23 times the business cycle volatility of real GDP, or nearly five times the volatility of business fixed investment. As noted above, the extreme volatility of $\mathrm{VC}$ activity resembles the volatility of inventory investment, which like VC activity is a small share of GDP, yet accounts for nearly half of the decline in GDP during a recession.

Figure 2 shows the cyclical pattern of aggregate exits from ventures and real GDP. The correlation is 0.38 , indicating that VC exit is less cyclical relative to VC entry. Still, the correlation between the cyclical VC-based entrepreneurship measure and cyclical GDP is substantially higher than previous work. For example, Koellinger and Thurik (2012) report a low average contemporaneous correlation of 0.06 between global cyclical GDP and the business ownership-based entrepreneurship measure. Parker, Congregado, and Golpe (2012) report a correlation of 0.05 between cyclical GDP and self-employment based entrepreneurship measure for the UK.

Figures 3 and 4 show the cyclical patterns of entry and exit at the sectoral level. As shown in Table 1, the IT sector VC entry and exit correlations are closer to the aggregate. The VC entry and exit cyclical in the LS sector, however, is least correlated with GDP. The sectoral volatility patterns reveal some variation, but taken together, underscore the high cyclical volatility in VC activity. 


\section{ii. Cross-correlations}

Table 2 shows the business cycle cross-correlations between real GDP and entry. The contemporaneous correlation is the largest for both aggregate and sector levels. This indicates that VC entry is coincident with the U.S. business cycle and does not show a leading or lagging pattern.

Table 3 shows the business cycle cross-correlations between real GDP and VC exit. For aggregate $\mathrm{VC}$ exit, the largest correlation indicates that aggregate $\mathrm{VC}$ exit deals lag the business cycle by two quarters. An increase in economic activity, for example, leads to the largest increase in VC exit deals two quarters later. Similarly, at the sector level, VC exit deals lag the cycle by one to two quarters. Overall, we find that VC exit deals do not lead the cycle at either the aggregate or the sectoral levels.

\subsection{Causality}

Does VC activity plays a causal role in driving economic activity? We conduct bi-variate Granger causality tests to check whether VC activity predicts future economic activity. We estimate the following regressions

$$
\begin{aligned}
Y_{t} & =\phi+\sum_{k=1}^{K} \alpha_{k} Y_{t-k}+\sum_{k=1}^{K} \beta_{k} V C_{t-k}^{i}+\varepsilon_{t} \\
V C_{t}^{i} & =\psi+\sum_{k=1}^{K} \delta_{k} Y_{t-k}+\sum_{k=1}^{K} \gamma_{k} V C_{t-k}^{i}+\nu_{t}
\end{aligned}
$$

where $Y_{t}$ is the cyclical real GDP, $V C_{t}^{i}$ is cyclical VC activity and $i=\{$ Entry, Exit $\}$, and $\varepsilon_{t}$ and $\nu_{t}$ are the error terms. We then test the null hypothesis $H_{0}: \beta_{1}=\ldots=\beta_{K}=0$ (i.e., $V C_{t}^{i}$ does not Granger-cause $Y_{t}$ ) for (1) and the reverse-causality hypothesis that $H_{0}: \delta_{1}=\ldots=\delta_{K}=0$ (i.e., $Y_{t}$ does not Granger-cause $\left.V C_{t}^{i}\right)$ for (2).

Panel (a) in Table 4 shows the $F$-test statistics along with the $5 \%$ critical value for aggregate data. The $F$-statistics is larger than the critical value hence we reject both null hypotheses. This finding indicates bi-directional Granger causality between cyclical VC entry and real GDP at the aggregate level. That is, VC entry predicts aggregate economic activity, and vice versa. Panel (b) shows the results for the sectors. For all three sectors, we once again find clear evidence of bi-directional Granger causality. The evidence, therefore, paints the same picture at both the 
aggregate and sector levels.

Panel (a) in Table 5 shows the Granger causality tests for VC exit. At the aggregate level we find bi-directional causality similar to the results for $\mathrm{VC}$ entry. The $F$-statistics value is larger than the critical value at the $5 \%$ level rejecting the null of no Granger causality. Thus, the cyclicality in total number of deals both predicts and is predicted by cyclical real GDP. Panel (b) shows the causality results for VC exit at the sector level. We find bi-directional causality for both LS and NHT sectors. For the IT sector, however, we do not reject the null that cyclical output does not Granger-cause VC exit. There is, therefore, some evidence of causality running from VC exit to output in this sector.

Overall, the results predominantly indicate bi-directional Granger causality. Since VC activity is a measure of entrepreneurship, we interpret a bi-directional relationship between entrepreneurship and output.

\subsection{VAR analysis}

How does economic activity respond to shocks emanating from VC activity? What fraction of the variation in real GDP is accounted for by entrepreneurship as measured by VC activity? To answer these questions we use VAR analysis and consider a simple bi-variate VAR analysis with the following

$$
\left[\begin{array}{c}
Y_{t} \\
V C_{t}^{i}
\end{array}\right]=\left[\begin{array}{ll}
B^{11}(L) & B^{12}(L) \\
B^{21}(L) & B^{22}(L)
\end{array}\right]\left[\begin{array}{c}
Y_{t-1} \\
V C_{t-1}^{i}
\end{array}\right]+\left[\begin{array}{c}
e_{1 t} \\
e_{2 t}
\end{array}\right]
$$

where $B^{k j}(L)$ is a polynomial with four lags, $B^{k j}(0)=1, E_{t}\left[e_{t} e_{t}^{\prime}\right]=\Sigma_{e}$ is the variance-covariance matrix with $e_{t}=\left[\begin{array}{ll}e_{1 t} & e_{2 t}\end{array}\right]^{\prime}$. We consider the standard Cholesky orthogonalization to identify a real GDP shock (denoted at $\eta_{t}^{G D P}$ ) and a VC activity (or entrepreneurship) shock denoted as $\eta_{t}^{V C^{i}}$, respectively, as follows. Let $\Sigma_{e}=G G^{\prime}$ and $e_{t}=G^{-1} \eta_{t}$, where $\eta_{t}=\left[\eta_{t}^{G D P} \eta_{t}^{V C^{i}}\right]$ is the vector of orthogonal shocks, $E\left[\eta_{t} \eta_{t}^{\prime}\right]=I$, and $G^{-1}$ is a lower triangular matrix. The Cholesky orthogonalization in this case implies the $Y_{t}$ responds only to $\eta_{t}^{G D P}$ contemporaneously but not to $\eta_{t}^{V C^{i}}$. There is no a-priori reason for this ordering. In fact, given the bi-directional Granger 
causality result, we consider the reverse ordering

$$
\left[\begin{array}{c}
V C_{t}^{i} \\
Y_{t}
\end{array}\right]=\left[\begin{array}{cc}
\tilde{B}^{11}(L) & \tilde{B}^{12}(L) \\
\tilde{B}^{21}(L) & \tilde{B}^{22}(L)
\end{array}\right]\left[\begin{array}{c}
V C_{t-1}^{i} \\
Y_{t-1}
\end{array}\right]+\left[\begin{array}{c}
\tilde{e}_{1 t} \\
\tilde{e}_{2 t}
\end{array}\right]
$$

with $\tilde{\eta}_{t}=\left[\eta_{t}^{V C^{i}} \eta_{t}^{G D P}\right]$. The Cholesky orthogonalization in this case implies the $V C_{t}^{i}$ responds only to $\eta_{t}^{V C^{i}}$ contemporaneously but not to $\eta_{t}^{G D P}$.

\section{i. Impulse-responses}

Figures 5 to 8 show the impulse response functions, along with one-standard error confidence bands, to a particular one standard deviation shock based on the specifications (3) and (4). As shown in the first column of Figure 5, output rises in a hump-shaped manner after a positive GDP shock, reaching a peak in the third quarter (marked as 2 in the figure). The response is statistically significant. At the same time, $\mathrm{VC}$ entry also increases in a hump-shaped manner reaching a peak around the same time as output. A positive VC entry shock that significantly increases VC entry does not have an impact effect on GDP by construction (specification (3)) as shown in the second

column of Figure 5. But there is a small positive effect on GDP, which is significant in the second quarter.

Column 1 in Figure 6 shows a significant increase inVC exit after a positive GDP shock. A positive shock to VC exit (column 2), does not affect GDP on impact by construction, but after the first quarter, there is a statistically significant hump-shaped response of GDP.

Figures 7 and 8 display the impulse responses for the VAR specification in (4) where we change the ordering of the two variables. As shown in Figure 7, $\mathrm{VC}$ entry shock now has a relatively stronger positive effect on GDP, which reaches a peak effect in the third quarter. The GDP shock, on the other hand, has a somewhat muted effect on VC entry. Figure 8 shows a similar pattern. The effect of a VC exit shock on GDP is more pronounced but the effect of a positive GDP shock on exits is muted, although it positive and statistically significant in the second quarter.

Overall, the impulse response analysis sheds light on the effects of both real GDP and VC shocks on these two variables. The effects we document are consistent with the unconditional correlations and the bi-variate causality results documented above. 


\section{ii. Variance decompositions}

In this section we present the results of variance decompositions for up to 8 quarters. ${ }^{8}$ The variance decompositions reveal the fraction of total cyclical variation accounted for by a particular shock. The top panel in Figure 9 shows the decomposition of cyclical real GDP accounted for by the real GDP shock (shown in black) and the VC entry shock (shown in blue). The fraction of variation in cyclical GDP accounted for by VC entry at an 8 quarter horizon is very small (as shown in blue). The bottom panel shows the decomposition of VC entry. At an 8 quarter horizon, cyclical GDP accounts for nearly a third of the variation in VC entry. The remaining two-thirds is accounted for by VC entry itself.

Figure 10 shows that at an 8 quarter horizon, the share of $\mathrm{VC}$ exit shock in accounting for the variation in cyclical GDP is about 5 percent (top panel). Similarly, at the same horizon, the share of cyclical GDP shock in accounting for the variation in $\mathrm{VC}$ exit is just over 5 percent (bottom panel).

\section{Implications for Policy}

Venture Capital (VC) is viewed as an important intermediary in financial markets, enabling entrepreneurial activity by providing capital to firms that would otherwise have difficulty in the financial markets (Gompers and Lerner (2001)). Because of this, it is an important topic for public policy. Entrepreneurship has become a "bona fide focus of public policy" (Audretsch, Grilo, and Thurik (2007)). In this paper, our focus is on the entrepreneurship when looked through the lens of $\mathrm{VC}$ activity and the business cycle. Our findings can be used to better inform public policy and decision makers.

As evident from our stylized facts, VC activity in the US, as a measure of entrepreneurship, is more correlated with business cycles relative to alternative measures considered in the previous literature. This provides further support that public policy should take into account the cyclical nature of entrepreneurial activity, and we, therefore, propose that entrepreneurial policies should incorporate cyclicality. One obvious policy concern related to this cyclicality is the potential de-

\footnotetext{
${ }^{8}$ For brevity, we present the results based on specification (3) only.
} 
crease in innovative activity during economic downturns or protracted recessions. This may have detrimental effects on the economy and could potentially delay the subsequent recovery. Lerner (2002), for example, considers the cyclical nature of the VC industry and observes its dramatic decline during the 2001 trough. Entrepreneurship via VC in particular, have a significant influence on innovation and technological change in US (Florida and Kenney (1988); Kortum and Lerner (2000)). We provide additional evidence that the role of public policy can be helpful in this context.

Brander, Du, and Hellmann (2014), for example, have pointed out the importance of Governmentsponsored VC (GVC) and that it augments Private VC (PVC) and their mix facilitates successful VC exit. The differences across sectors that we document, suggest that industry specific factors are also important in thinking about government policies. Moreover, our findings display the contemporaneous relationship of VC entry with economic activity and a two-quarter lagged relationship of $\mathrm{VC}$ exit with the business cycle, which is important for the timing of public policy. There are various entrepreneurship and $\mathrm{VC}$ policies and further research is necessary towards this direction (Holtz-Eakin (2000); Gompers and Lerner (2001); Audretsch, Grilo, and Thurik (2007)), considering the cyclical nature of entrepreneurial activity. Taking into account the cyclicality of VC activity, at both the aggregate and the sectoral levels, in the design of optimal policy could be beneficial for the society.

\section{Conclusions}

In this paper we contribute to the literature that studies the relationship between entrepreneurship and the business cycle. We consider US venture capital activity as a measure of entrepreneurship and study its relationship with the business cycle both at the aggregate and sectoral levels. Although VC as a share of total GDP is relatively small and highly volatile, as a measure of entrepreneurship it offers some advantages relative to those previously considered in the literature. Among them are the coverage of entire US VC activity and the fact that it is a major driver of innovation.

We find that VC entry is relatively more procyclical than VC exit. But VC exit lags the business cycle by two quarters. Similar patterns exist at the sector level. There is bi-directional 
causality between cyclical VC activity and cyclical GDP. And that a shock to cyclical VC activity has a positive effect on cyclical GDP, although VC shocks account for a relatively small variation in cyclical GDP.

As recognized in the literature, timing and regulations, can affect high-performance ventures (Audretsch and Acs (1994); Acs and Szerb (2007); Acs, Braunerhjelm, Audretsch, and Carlsson (2009); Mason and Harrison (2002)). Therefore, it is important to understand the cyclical relationship between innovative entrepreneurial activity funded by venture capital and business cycles. From a policy perspective, taking into account cyclicality of $\mathrm{VC}$ activity at both the aggregate and the sectoral levels may help improve the design of optimal policy. The stylized facts that we have documented in the paper are a step in that direction. 


\section{References}

Acs, Zoltan J, Pontus Braunerhjelm, David B Audretsch, and Bo Carlsson, 2009, The knowledge spillover theory of entrepreneurship, Small business economics 32, 15-30.

Acs, Zoltan J, and Laszlo Szerb, 2007, Entrepreneurship, economic growth and public policy, Small Business Economics 28, 109-122.

Audretsch, David B, and Zoltan J Acs, 1994, New-firm startups, technology, and macroeconomic fluctuations, Small Business Economics 6, 439-449.

Audretsch, David B., Isabel Grilo, and Roy A. Thurik, 2007, Handbook of Research on Entrepreneurship Policy (Edward Elgar Publishing Limited).

Bernanke, Ben, and Mark Gertler, 1989, Agency costs, net worth, and business fluctuations, The American Economic Review 79, 14-31.

Bowen, Harry P, and Dirk De Clercq, 2008, Institutional context and the allocation of entrepreneurial effort, Journal of International Business Studies 39, 747-768.

Brander, J. A., Q. Du, and T. Hellmann, 2014, The effects of government-sponsored venture capital: International evidence, Review of Finance pp. 1-48.

Carlstrom, Charles T, and Timothy S Fuerst, 1997, Agency costs, net worth, and business fluctuations: A computable general equilibrium analysis, The American Economic Review pp. 893-910.

Cochrane, John H, 2005, The risk and return of venture capital, Journal of Financial Economics 75, 3-52.

Cooper, Arnold C., 1971, The Founding of Technology based Firms (The Center for Venture Management: Milwaukee,US).

Da Rin, Marco, Thomas F. Hellmann, and Manju Puri, 2013, A survey of venture capital research, in George M. Constantinides Constantinides, Milton Harris, and Rene M. Stulz, ed.: Handbook of the Economics of Finance . chap. 8, pp. 573-648 (Elsevier). 
Douglas, Evan J, and Dean A Shepherd, 2000, Entrepreneurship as a utility maximizing response, Journal of Business Venturing 15, 231-251.

Douglass, Merrill E, 1976, Relating education to entrepreneurial success, Business Horizons 19, $40-44$.

Eurostat/OECD, 2007, Eurostat-OECD Manual on Business Demography Statistics.

Faria, João Ricardo, Juan Carlos Cuestas, and Luis A. Gil-Alana, 2009, Unemployment and entrepreneurship: A cyclical relation?, Economics Letters 105, 318-320.

Faria, João Ricardo, Juan Carlos Cuestas, and Estefanía Mourelle, 2010, Entrepreneurship and unemployment: A nonlinear bidirectional causality?, Economic Modelling 27, 1282-1291.

Florida, Richard, and Martin Kenney, 1988, Venture capital-financed innovation and technological change in the USA, Research Policy 17, 119-137.

Golpe, Antonio, 2009, Self-employment and business cycles, Ph.D. thesis University of Huelva Spain.

Gompers, Paul A, and Josh Lerner, 2001, The venture capital revolution, Journal of Economic Perspectives 15, 145-168.

Hoad, William Marvin, and Peter Rosko, 1964, Management factors contributing to the success or failure of new small manufacturers . vol. 41 (Bureau of Business Research, Graduate School of Business Administration, University of Michigan).

Holtz-Eakin, Douglas, 2000, Public policy toward entrepreneurship, Small Business Economics 15, $283-291$.

Jo, Hyungrae, and Jinjoo Lee, 1996, The relationship between an entrepreneur's background and performance in a new venture, Technovation 16, 161-171.

Khan, Aubhik, 2003, The role of inventories in the business cycle, Business Review pp. 38-46. 
Kihlstrom, Richard E, and Jean-Jacques Laffont, 1979, A general equilibrium entrepreneurial theory of firm formation based on risk aversion, Journal of Political Economy 87, 719-748.

Knight, Frank H, 1921, Risk, uncertainty and profit (Courier Corporation).

Koellinger, Philipp D, and A Roy Thurik, 2012, Entrepreneurship and the business cycle, The Review of Economics and Statistics 94, 1143-1156.

Kortum, Samuel, and Josh Lerner, 2000, Assessing the contribution of venture capital to innovation, The RAND Journal of Economics 31, 674-692.

Kuznets, Simon, 1940, Schumpeter's business cycles, The American Economic Review 30, 257-271.

Lerner, Josh, 2002, Boom and bust in the venture capital industry and the impact on innovation, NOM Working Paper 03-13 Harvard University.

Mason, Colin M, and Richard T Harrison, 2002, Is it worth it? the rates of return from informal venture capital investments, Journal of Business Venturing 17, 211-236.

Pardo, Cristian, 2012, Risk aversion and business cycles: An empirical analysis, The Quarterly Review of Economics and Finance 52, 413-426.

— , 2013, Entrepreneurial risk aversion, net worth effects and real fluctuations, Review of Financial Economics 22, 158-168.

Parker, Simon C, 2009, The Economics of Entrepreneurship (Cambridge University Press).

— - Emilio Congregado, and Antonio A Golpe, 2012, Is entrepreneurship a leading or lagging indicator of the business cycle? evidence from UK self-employment data, International Small Business Journal 30, 736-753.

Rampini, Adriano A, 2004, Entrepreneurial activity, risk, and the business cycle, Journal of Monetary Economics 51, 555-573.

Roberts, E. B, 1968, A basic study of innovators: How to keep and capitalize on their talents, Reasearch Management 11, 249-266. 
Sahlman, William A, 1990, The structure and governance of venture-capital organizations, Journal of financial economics 27, 473-521.

Sandberg, William R, and Charles W Hofer, 1987, Improving new venture performance: The role of strategy, industry structure, and the entrepreneur, Journal of business venturing 2, 5-28.

Schumpeter, Joseph A., 1934, The Theory of Economic Development: An Inquiry into Profits, Capital, Credit, Interest, and the Business Cycle . vol. 46 of Harvard Economic Studies (Harvard University Press).

Van de Ven, Andrew H, Roger Hudson, and Dean M Schroeder, 1984, Designing new business startups: Entrepreneurial, organizational, and ecological considerations, Journal of management 10, $87-107$. 
Figure 1: Entry of venture capital-funded companies (cyclical, blue) and real GDP (cyclical, red)

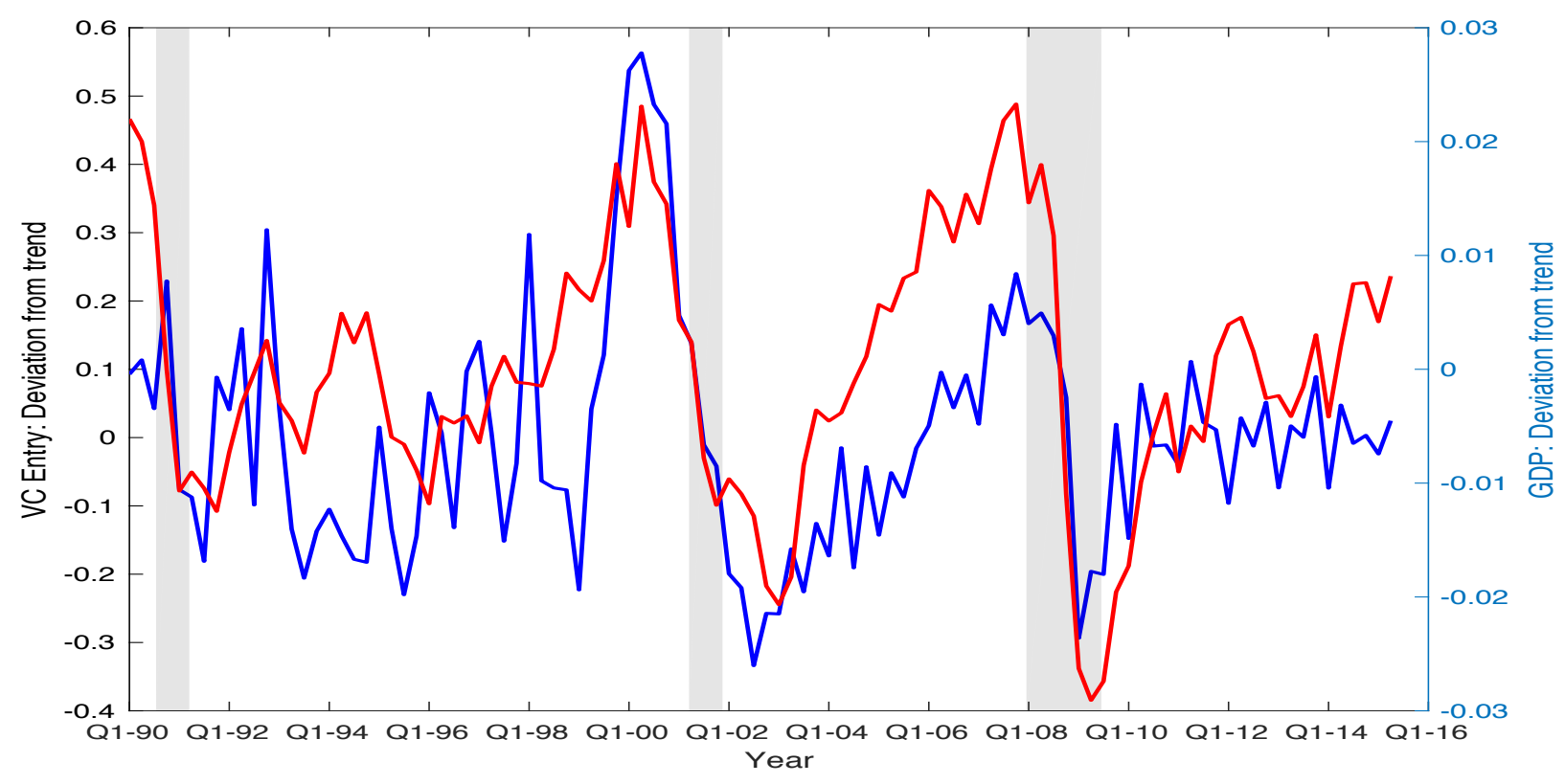


Figure 2: Exit from ventures into deals (cyclical, blue) and real GDP (cyclical, red)

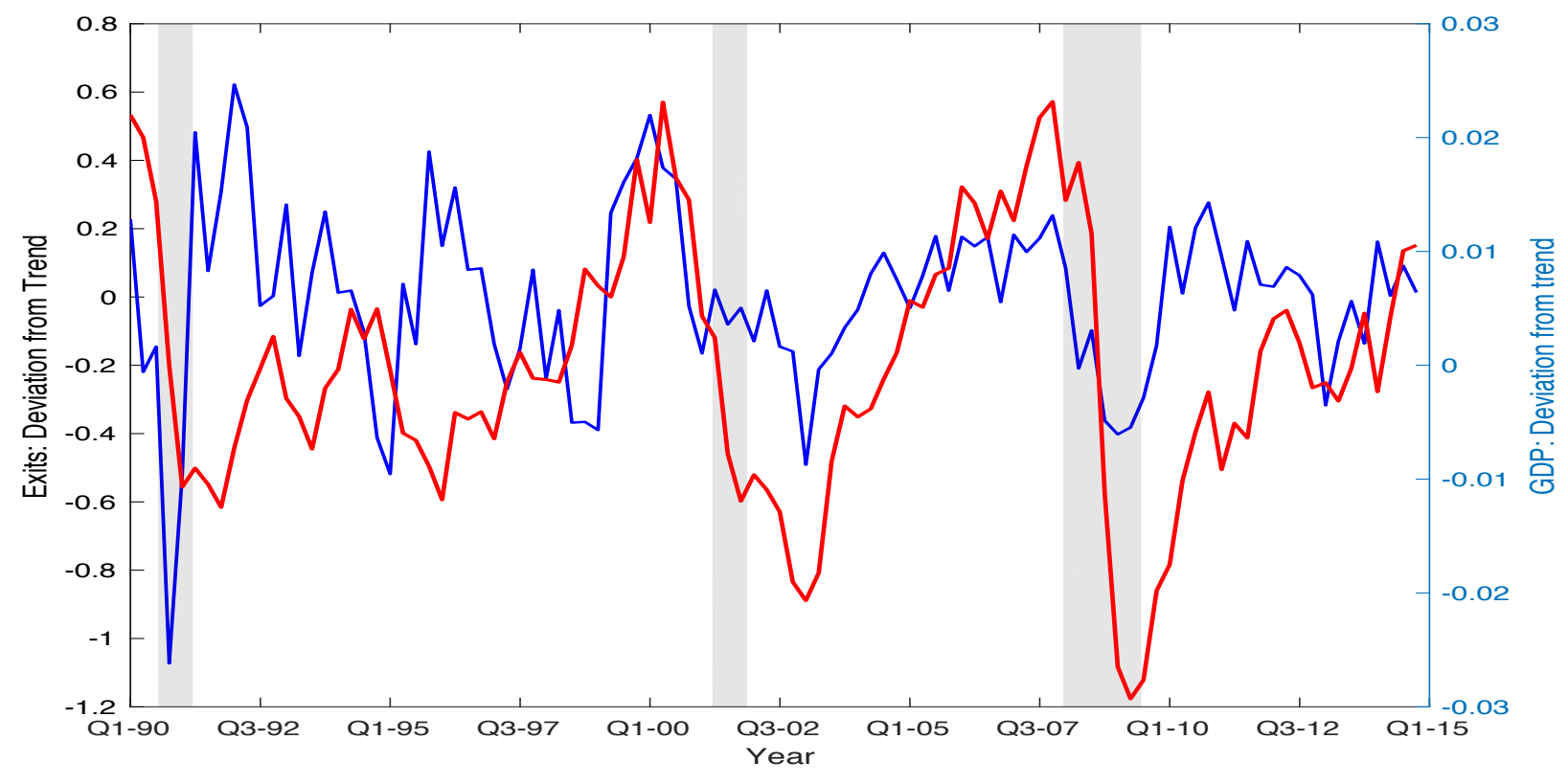


Figure 3: Entry of VC-funded companies (cyclical), by sectors. IT, LS, and NHT
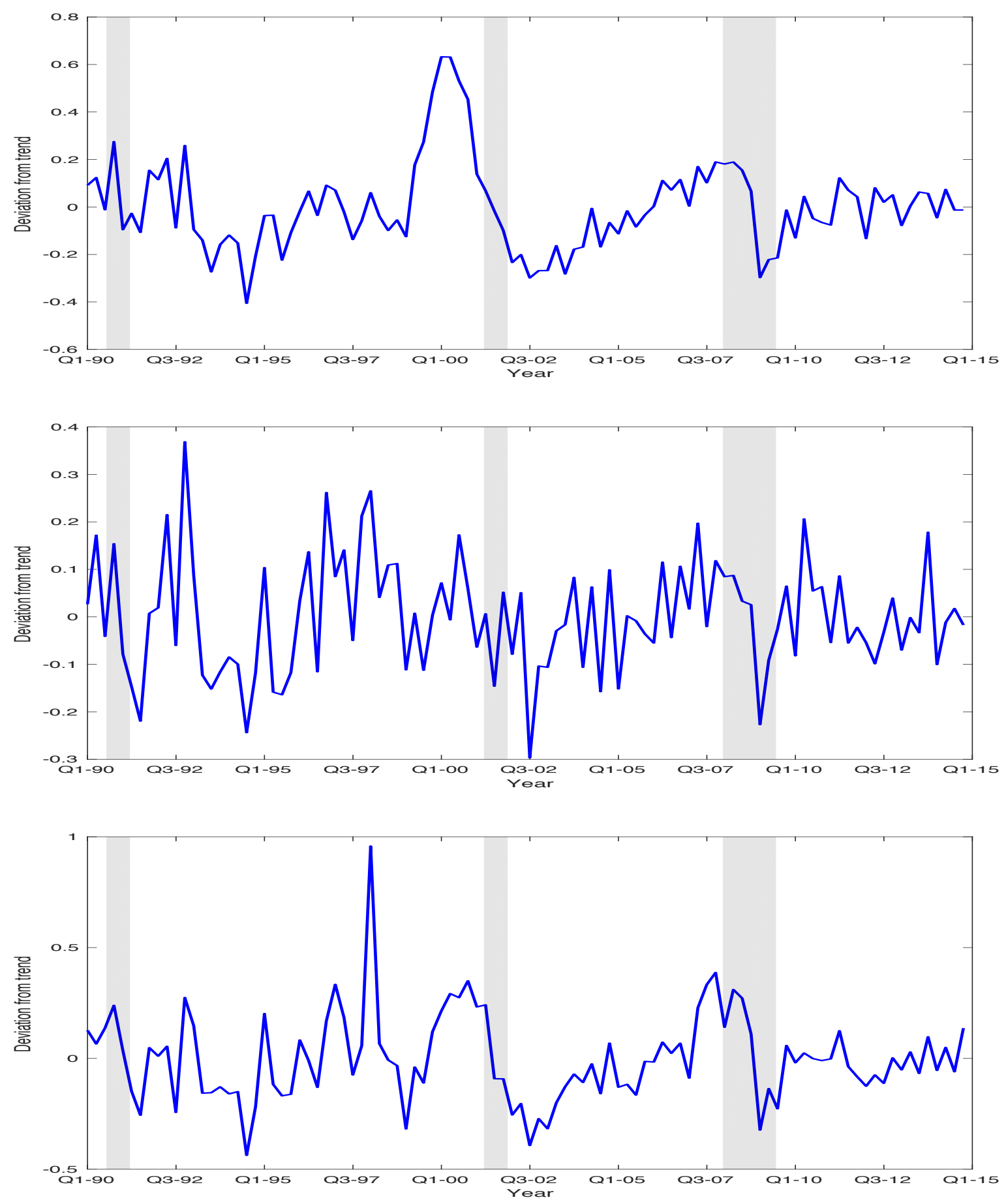
Figure 4: Exit deals (cyclical), by sectors. IT, LS, and NHT
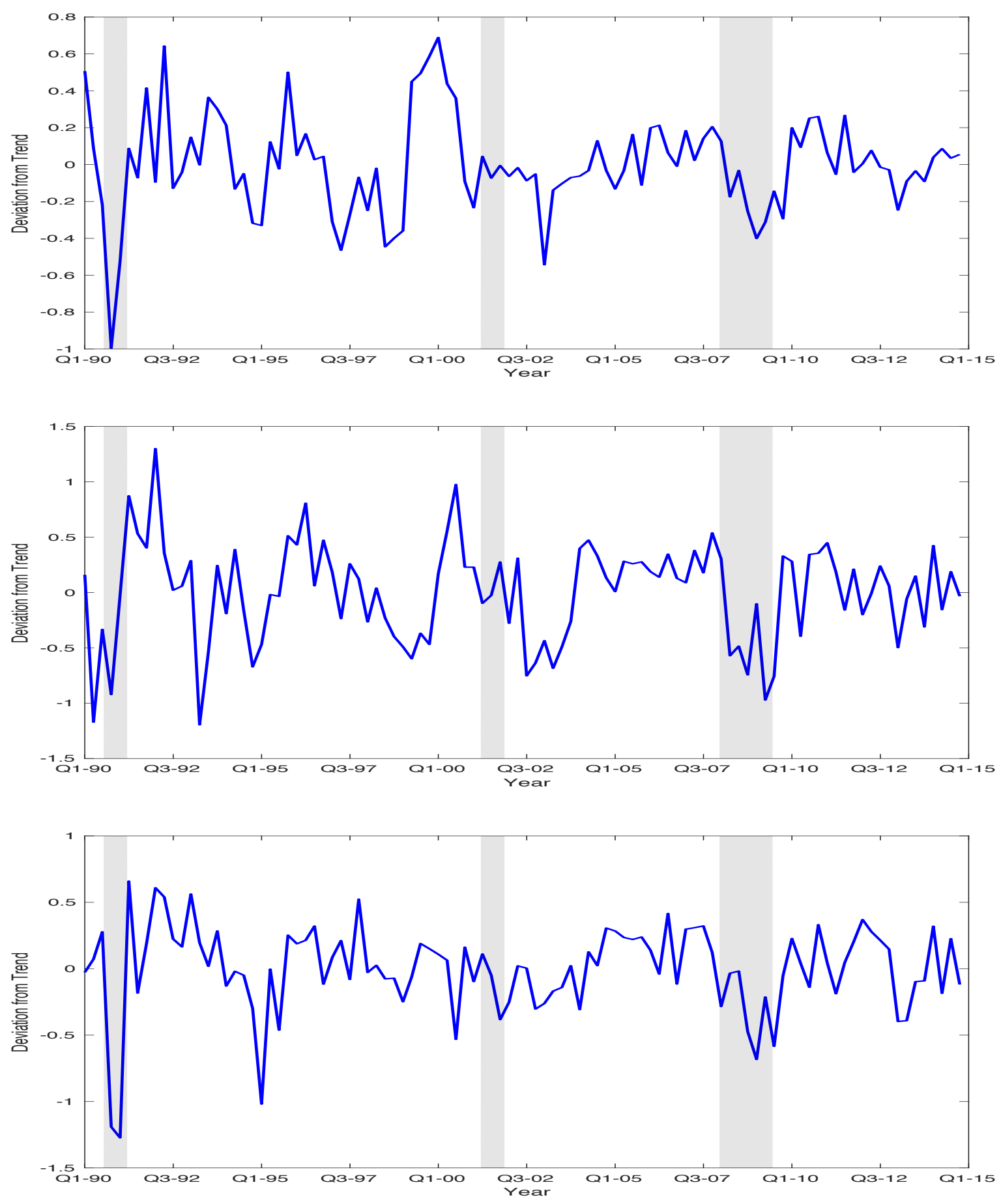

Notes: $\mathrm{IT}=$ Information Technology, LS $=$ Life Sciences, and NHT $=$ Non-High Technology. 
Figure 5: Impulse Responses to a VC entry (companies) shock

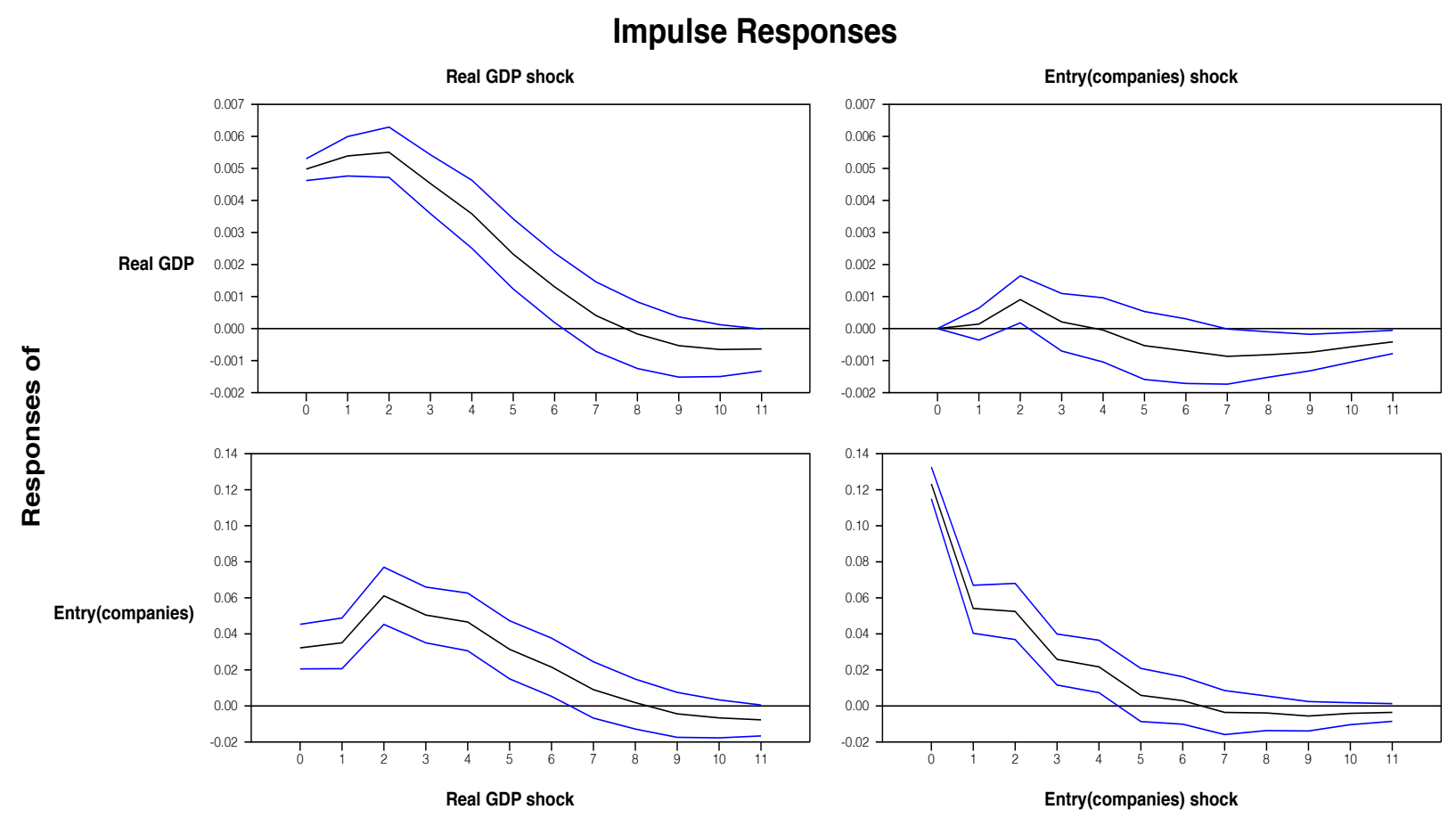

Notes: The ordering of the variables in the VAR is Real GDP, VC entry. The black line shows the response and the blue line shows one-standard error confidence bands. 
Figure 6: Impulse Responses to a VC exit (deals) shock

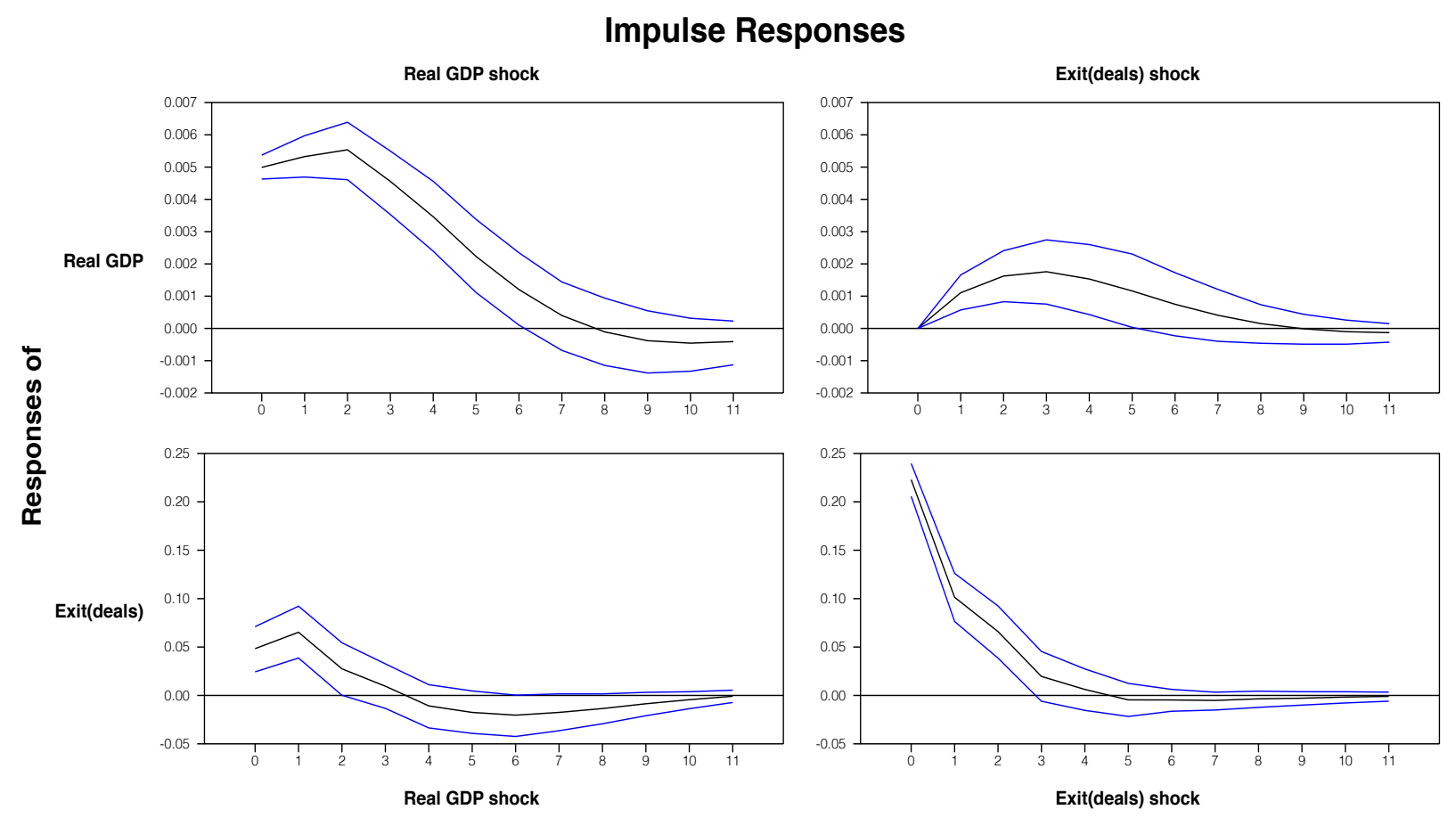

Notes: The ordering of the variables in the VAR is Real GDP, VC entry. The black line shows the response and the blue line shows one-standard error confidence bands. 
Figure 7: Impulse Responses to a VC entry (companies) shock

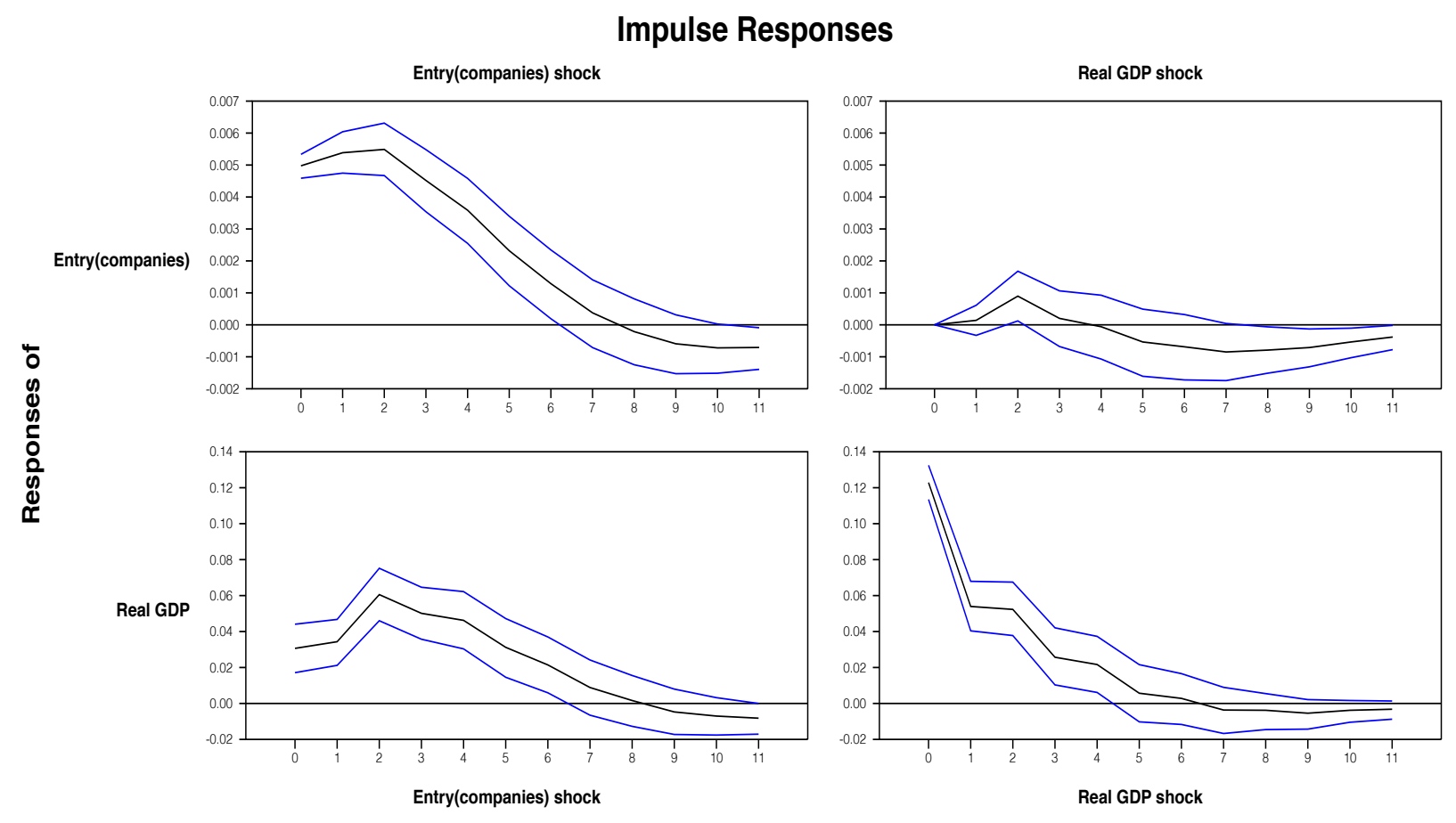

Notes: The ordering of the variables in the VAR is VC entry, GDP. The black line shows the response and the blue line shows one-standard error confidence bands. 
Figure 8: Impulse Responses to a VC exit (deals) shock

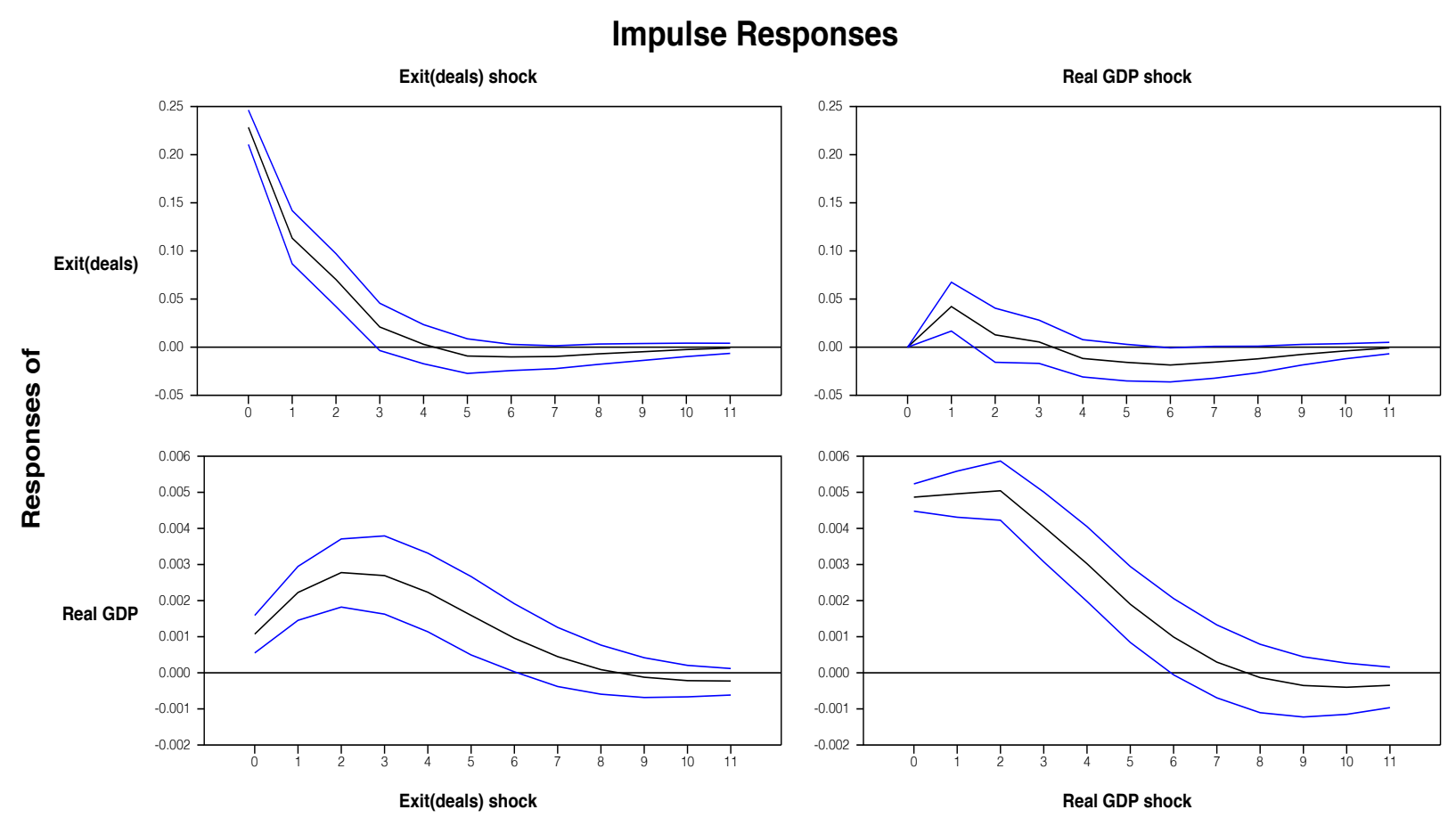

Notes: The ordering of the variables in the VAR is VC entry, GDP. The black line shows the response and the blue line shows one-standard error confidence bands. 
Figure 9: Variance Decomposition: GDP and Entry (companies)

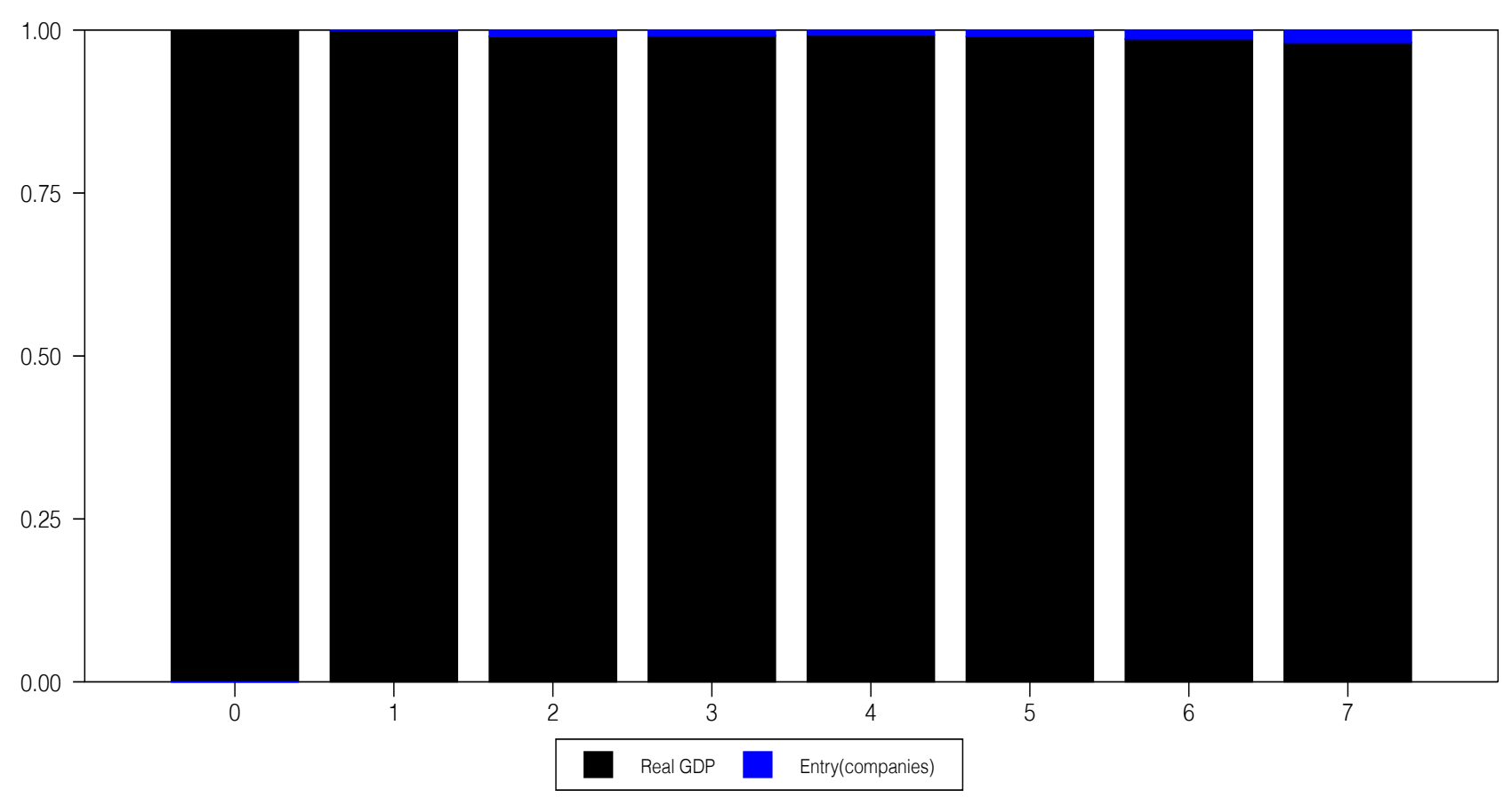

Decomposition of Real GDP

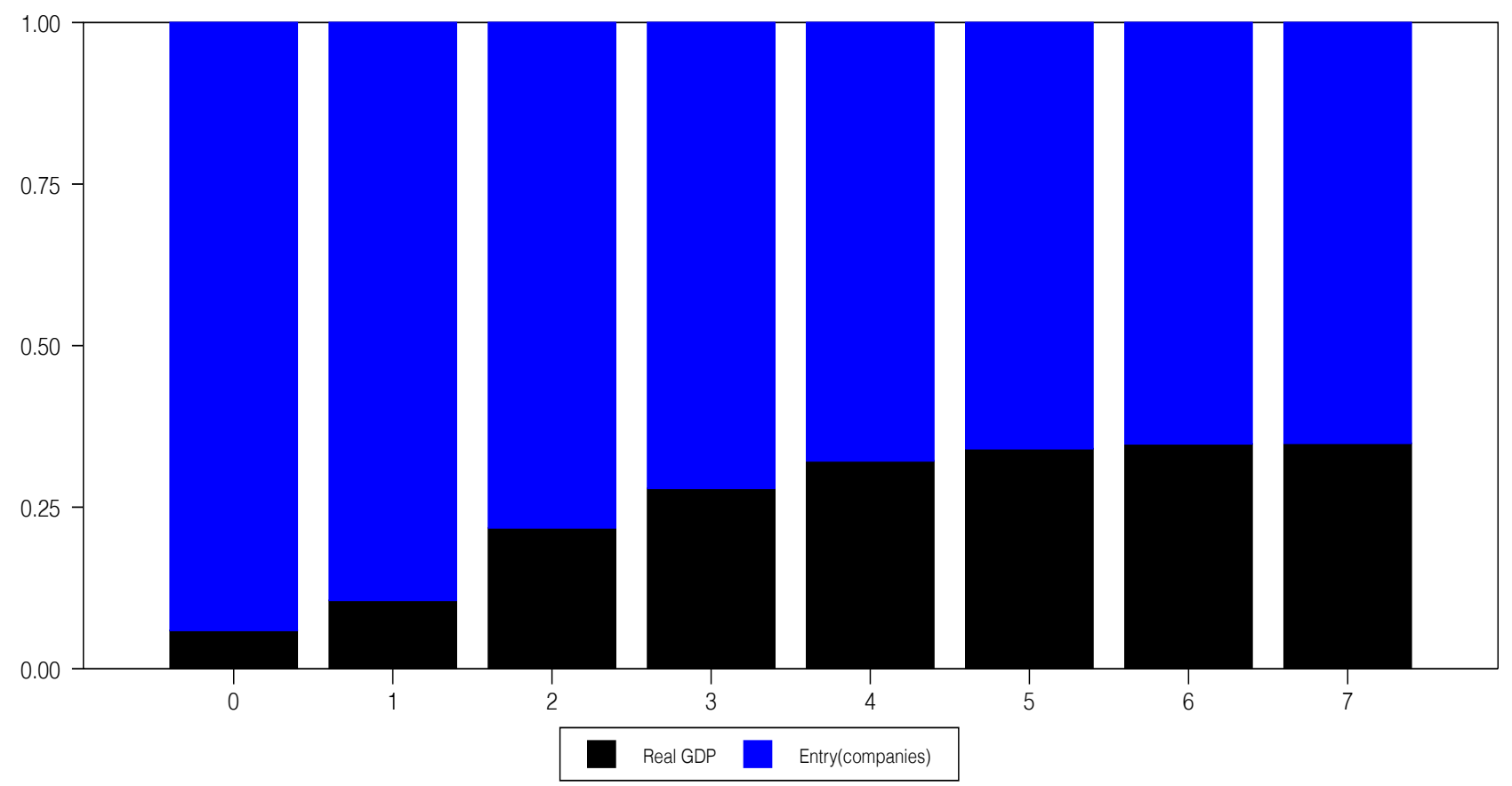

Decomposition of Entry(companies) 
Figure 10: Variance Decomposition: GDP and Exit (deals)

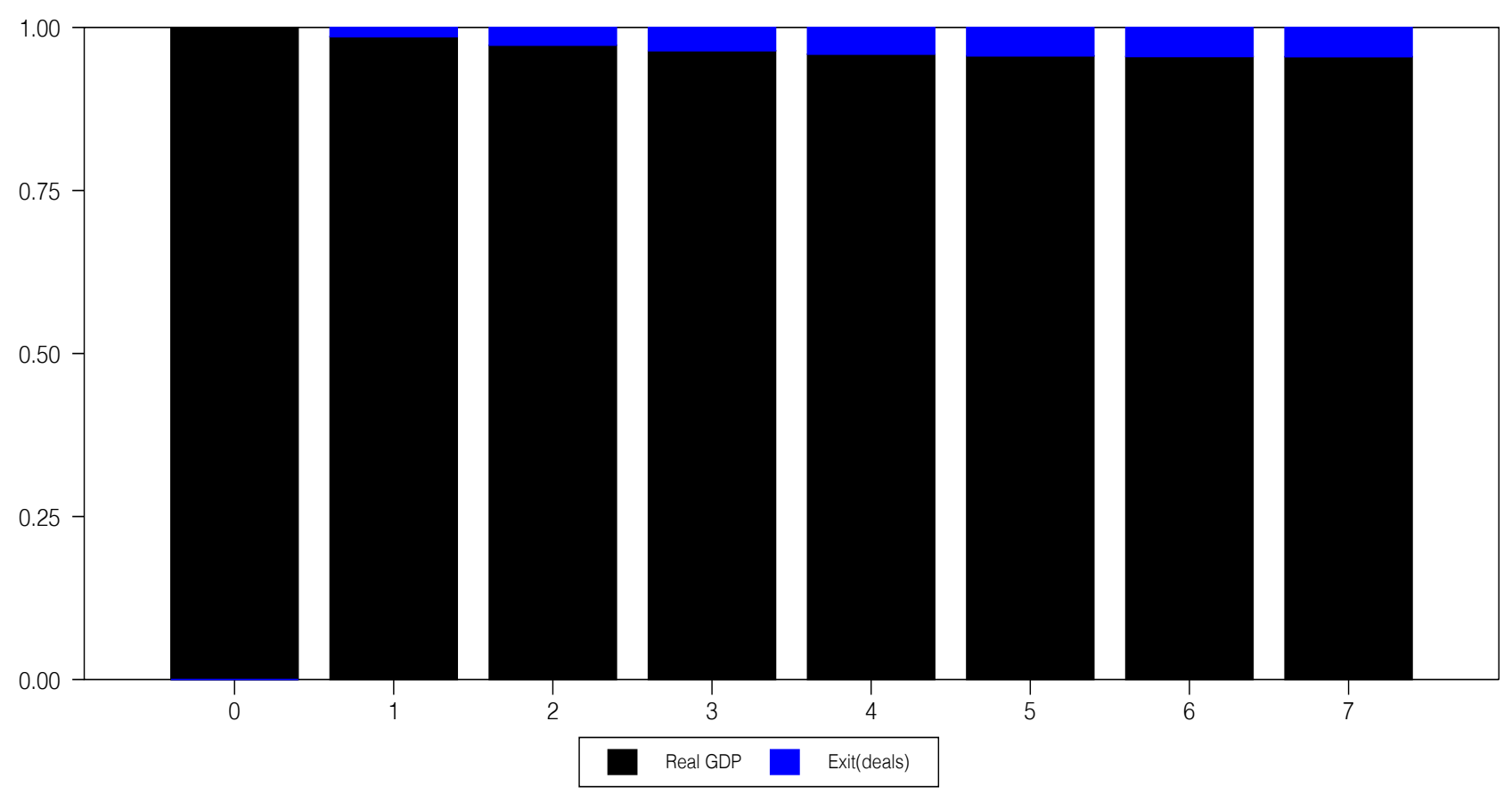

Decomposition of Real GDP

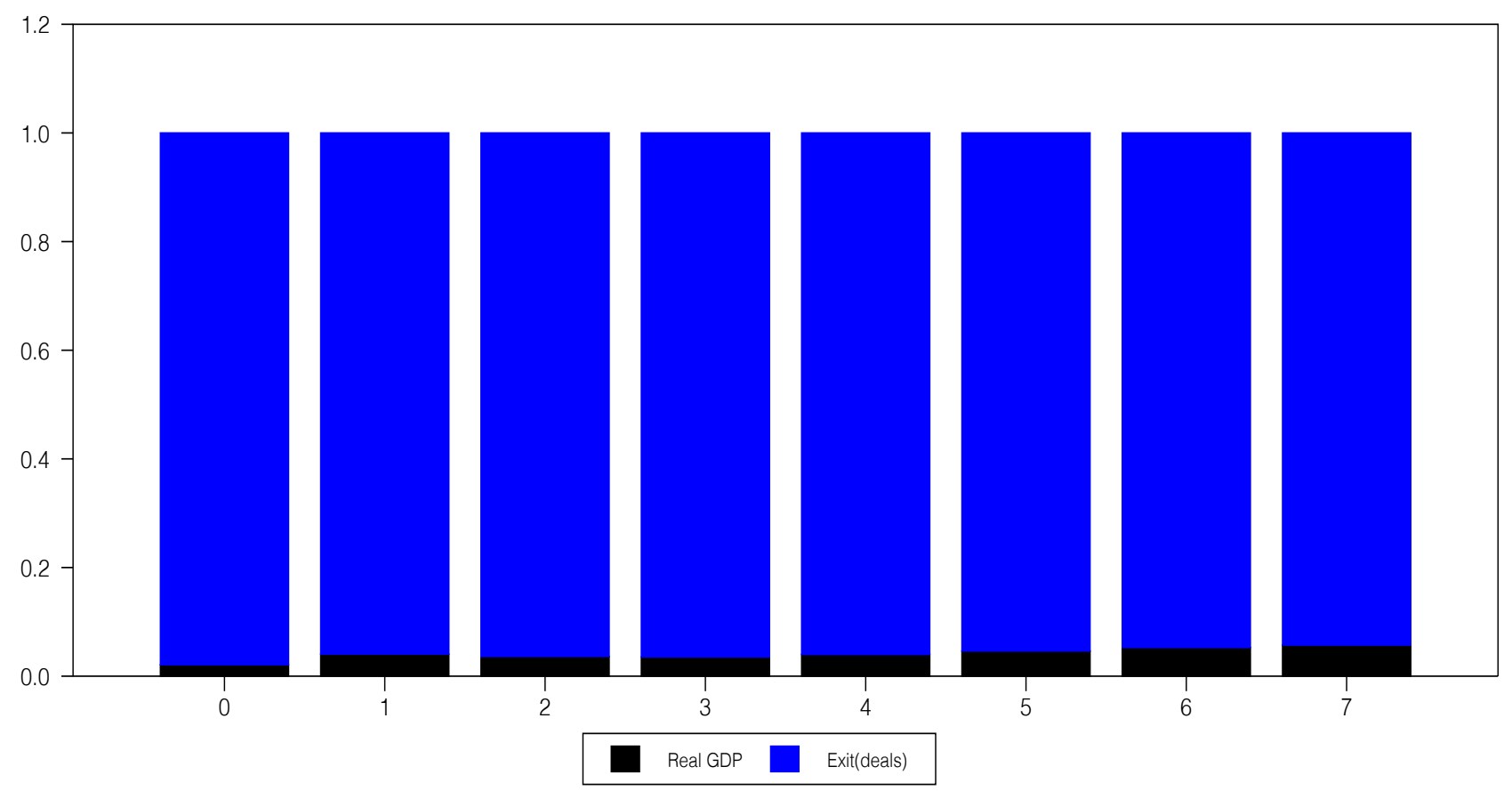

Decomposition of Exit(deals) 
Table 1: Correlations and relative volatility

\begin{tabular}{|c|c|c|c|c|}
\hline & \multicolumn{2}{|r|}{ Entry } & \multicolumn{2}{|r|}{ Exits } \\
\hline & Correlation & Relative Volatility & Correlation & Relative Volatility \\
\hline Aggregate & 0.60 & 15.14 & 0.38 & 22.92 \\
\hline \multicolumn{5}{|l|}{ Sectors } \\
\hline IT & 0.59 & 16.58 & 0.30 & 23.60 \\
\hline NHT & 0.45 & 17.64 & 0.24 & 29.28 \\
\hline LS & 0.28 & 10.54 & 0.13 & 39.93 \\
\hline
\end{tabular}

Notes: Total aggregate entry over 1990Q1-2015Q2. Cyclical components were obtained using the Hodrick-Prescott filter with a smoothing parameter 1600. Sectoral data over 1990Q12014Q4. IT is Information Technology, LS is Life Sciences, NHT is Non-High Tech. 
Table 2: Cross-Correlations between real GDP $(Y)$ and VC-entry $(E)$

\begin{tabular}{lrrrr}
\hline & Aggregate & \multicolumn{3}{c}{ Sectors } \\
& & \multicolumn{1}{c}{ IT } & \multicolumn{1}{c}{ LS } & \multicolumn{1}{c}{ NHT } \\
& Companies & Companies & Companies & Companies \\
\hline $\operatorname{Corr}\left(Y_{t}, E_{t+8}\right)$ & -0.29 & -0.26 & 0.08 & -0.15 \\
$\operatorname{Corr}\left(Y_{t}, E_{t+7}\right)$ & -0.28 & -0.26 & 0.04 & -0.17 \\
$\operatorname{Corr}\left(Y_{t}, E_{t+6}\right)$ & -0.22 & -0.17 & 0.04 & -0.17 \\
$\operatorname{Corr}\left(Y_{t}, E_{t+5}\right)$ & -0.14 & -0.08 & 0.00 & -0.15 \\
$\operatorname{Corr}\left(Y_{t}, E_{t+4}\right)$ & 0.02 & 0.08 & 0.05 & -0.02 \\
$\operatorname{Corr}\left(Y_{t}, E_{t+3}\right)$ & 0.18 & 0.23 & 0.09 & 0.08 \\
$\operatorname{Corr}\left(Y_{t}, E_{t+2}\right)$ & 0.38 & 0.41 & 0.21 & 0.22 \\
$\operatorname{Corr}\left(Y_{t}, E_{t+1}\right)$ & 0.50 & 0.51 & 0.24 & 0.32 \\
$\operatorname{Corr}\left(Y_{t}, E_{t}\right)$ & $\mathbf{0 . 6 0}$ & $\mathbf{0 . 5 9}$ & $\mathbf{0 . 2 8}$ & $\mathbf{0 . 4 5}$ \\
$\operatorname{Corr}\left(Y_{t}, E_{t-1}\right)$ & 0.58 & 0.56 & 0.20 & 0.45 \\
$\operatorname{Corr}\left(Y_{t}, E_{t-2}\right)$ & 0.52 & 0.50 & 0.08 & 0.42 \\
$\operatorname{Corr}\left(Y_{t}, E_{t-3}\right)$ & 0.37 & 0.37 & -0.03 & 0.30 \\
$\operatorname{Corr}\left(Y_{t}, E_{t-4}\right)$ & 0.24 & 0.26 & -0.11 & 0.17 \\
$\operatorname{Corr}\left(Y_{t}, E_{t-5}\right)$ & 0.16 & 0.18 & -0.14 & 0.09 \\
$\operatorname{Corr}\left(Y_{t}, E_{t-6}\right)$ & 0.11 & 0.14 & -0.08 & 0.06 \\
$\operatorname{Corr}\left(Y_{t}, E_{t-7}\right)$ & 0.08 & 0.09 & -0.01 & 0.02 \\
$\operatorname{Corr}\left(Y_{t}, E_{t-8}\right)$ & 0.04 & 0.05 & 0.06 & -0.01 \\
\hline & & & &
\end{tabular}

Notes: Total aggregate entry over the 1990Q1-2015Q2 period. Cyclical components were obtained using the Hodrick-Prescott filter with a smoothing parameter 1600. The optimal lag-length in Granger causality test was chosen using the Bayesian Information Criterion. Sectoral data is over 1990Q1-2014Q4 period. IT is Information Technology, LS is Life Sciences, NHT is Non-High Tech. The largest correlations are shown in bold. 
Table 3: Cross-Correlations between real GDP $(Y)$ and VC-exit (deals)

\begin{tabular}{lrrrr}
\hline & Aggregate & \multicolumn{3}{c}{ Sectors } \\
& & IT & LS & NHT \\
\hline $\operatorname{Corr}\left(Y_{t}, E_{t+8}\right)$ & -0.11 & -0.19 & 0.00 & 0.09 \\
$\operatorname{Corr}\left(Y_{t}, E_{t+7}\right)$ & -0.12 & -0.19 & -0.02 & 0.06 \\
$\operatorname{Corr}\left(Y_{t}, E_{t+6}\right)$ & -0.03 & -0.08 & -0.02 & 0.12 \\
$\operatorname{Corr}\left(Y_{t}, E_{t+5}\right)$ & 0.10 & 0.04 & 0.06 & 0.21 \\
$\operatorname{Corr}\left(Y_{t}, E_{t+4}\right)$ & 0.25 & 0.20 & 0.12 & 0.31 \\
$\operatorname{Corr}\left(Y_{t}, E_{t+3}\right)$ & 0.35 & 0.31 & 0.23 & 0.31 \\
$\operatorname{Corr}\left(Y_{t}, E_{t+2}\right)$ & $\mathbf{0 . 4 0}$ & 0.40 & $\mathbf{0 . 2 5}$ & 0.31 \\
$\operatorname{Corr}\left(Y_{t}, E_{t+1}\right)$ & 0.38 & $\mathbf{0 . 4 0}$ & 0.22 & $\mathbf{0 . 3 2}$ \\
$\operatorname{Corr}\left(Y_{t}, E_{t}\right)$ & 0.26 & 0.30 & 0.12 & 0.24 \\
$\operatorname{Corr}\left(Y_{t}, E_{t-1}\right)$ & 0.09 & 0.14 & 0.04 & 0.04 \\
$\operatorname{Corr}\left(Y_{t}, E_{t-2}\right)$ & -0.05 & -0.01 & -0.00 & -0.11 \\
$\operatorname{Corr}\left(Y_{t}, E_{t-3}\right)$ & -0.12 & -0.07 & -0.06 & -0.24 \\
$\operatorname{Corr}\left(Y_{t}, E_{t-4}\right)$ & -0.07 & -0.03 & -0.05 & -0.19 \\
$\operatorname{Corr}\left(Y_{t}, E_{t-5}\right)$ & -0.05 & -0.04 & -0.00 & -0.16 \\
$\operatorname{Corr}\left(Y_{t}, E_{t-6}\right)$ & -0.01 & -0.02 & 0.02 & -0.13 \\
$\operatorname{Corr}\left(Y_{t}, E_{t-7}\right)$ & -0.02 & -0.01 & -0.03 & -0.13 \\
$\operatorname{Corr}\left(Y_{t}, E_{t-8}\right)$ & -0.04 & -0.05 & -0.04 & -0.13 \\
\hline \hline
\end{tabular}

Notes: Total aggregate exits over the 1990Q1-2015Q2 period. Cyclical components were obtained using the Hodrick-Prescott filter with a smoothing parameter 1600. The optimal lag-length in Granger causality test was chosen using the Bayesian Information Criterion. Sectoral data is over 1990Q1-2014Q4 period. IT is Information Technology, LS is Life Sciences, NHT is Non-High Tech. The largest correlations are shown in bold. 
Table 4: Granger-causality tests for real GDP and VC-funded companies

\begin{tabular}{|c|c|c|c|c|c|}
\hline & & & Aggregat & & \\
\hline & $H_{0}$ & Entry $\nrightarrow$ A $Y$ & $H_{0}:$ & Entry $\nrightarrow \rightarrow V C$ & Causality \\
\hline & F-test & $5 \%$ Crit. Value & F-test & $5 \%$ Crit. Value & \\
\hline & 4.56 & 2.70 & 5.67 & 3.94 & Entry $\rightleftarrows Y$ \\
\hline & & & Sectors & & \\
\hline & $H_{0}$ & Entry $\nrightarrow$ † $Y$ & $H_{0}:$ & Entry $\nrightarrow \rightarrow V C$ & Causality \\
\hline Sector & F-test & $5 \%$ Crit. Value & F-test & $5 \%$ Crit. Value & \\
\hline IT & 4.84 & 2.70 & 4.36 & 2.47 & Entry $\rightleftarrows Y$ \\
\hline LS & 4.65 & 3.94 & 3.38 & 3.09 & Entry $\rightleftarrows Y$ \\
\hline NHT & 4.79 & 3.94 & 11.52 & 3.93 & Entry $\rightleftarrows Y$ \\
\hline
\end{tabular}

Notes: Data over the 1990Q1-2015Q2 period. Cyclical components were obtained using the Hodrick-Prescott filter with a smoothing parameter 1600. The optimal lag-length in Granger causality test was chosen using the Bayesian Information Criterion. $\sigma_{e} / \sigma_{y}$ denotes volatility of $\mathrm{VC}$ entry relative to output. 
Table 5: Granger-causality tests for real GDP and Exits (total number of deals)

\begin{tabular}{lccccc}
\hline \hline \multicolumn{5}{c}{ (a) Aggregate } \\
& $H_{0}:$ Exits $\nrightarrow$ $\rightarrow Y$ & $H_{0}: Y \not \rightarrow$ Exits & Causality \\
& F-test & $5 \%$ Crit. Value & F-test & $5 \%$ Crit. Value & \\
& 9.25 & 3.94 & 7.22 & 2.20 & Exits $\rightleftarrows Y$ \\
& \multicolumn{5}{c}{ (b) Sectors } \\
& & & & \\
& $H_{0}:$ Exits $\nrightarrow$ $\rightarrow Y$ & $H_{0}: Y \not \rightarrow$ Exits & Causality \\
IT & F-test & $5 \%$ Crit. Value & F-test & $5 \%$ Crit. Value & \\
LS & 8.24 & 3.94 & 3.66 & 3.94 & Exits $\rightarrow Y$ \\
NHT & 6.83 & 3.94 & 5.41 & 2.04 & Exits $\rightleftarrows Y$ \\
& 5.07 & 3.94 & 4.11 & 2.11 & Exits $\rightleftarrows Y$ \\
\hline
\end{tabular}

Notes: Total aggregate exits over the 1990Q1-2015Q2 period. Cyclical components were obtained using the Hodrick-Prescott filter with a smoothing parameter 1600. The optimal lag-length in Granger causality test was chosen using the Bayesian Information Criterion. Sectoral data is over 1990Q1-2014Q4 period. IT is Information Technology, LS is Life Sciences, NHT is Non-High Tech. $\sigma_{e x} / \sigma_{y}$ denotes volatility of VC exits relative to output. 